\title{
Article \\ Elemental Chemometrics as Tools to Depict Stalked Barnacle (Pollicipes pollicipes) Harvest Locations and Food Safety
}

\author{
Bernardo Duarte ${ }^{1,2, *(\mathbb{D})}$, Renato Mamede ${ }^{1}\left(\mathbb{D}\right.$, Irina A. Duarte ${ }^{1}$, Isabel Caçador ${ }^{1,2}$, Susanne E. Tanner ${ }^{1,3}$, \\ Marisa Silva ${ }^{1,2}$, David Jacinto ${ }^{4}$ (D) Teresa Cruz ${ }^{4,5}$ and Vanessa F. Fonseca ${ }^{1,3}$ (D)
}

1 MARE-Marine and Environmental Sciences Centre, Faculdade de Ciências, Universidade de Lisboa, Campo Grande, 1749-016 Lisbon, Portugal; rjmamede@fc.ul.pt (R.M.); iaduarte@fc.ul.pt (I.A.D.); micacador@fc.ul.pt (I.C.); setanner@fc.ul.pt (S.E.T.); mpdsilva@fc.ul.pt (M.S.); vffonseca@fc.ul.pt (V.F.F.)

2 Departamento de Biologia Vegetal, Faculdade de Ciências, Universidade de Lisboa, Campo Grande, 1749-016 Lisboa, Portugal

3 Departamento de Biologia Animal, Faculdade de Ciências, Universidade de Lisboa, Campo Grande, 1749-016 Lisboa, Portugal

4 MARE-Marine and Environmental Sciences Centre, Laboratório de Ciências do Mar, Universidade de Évora, 7521-903 Sines, Portugal; djacinto@uevora.pt (D.J.); tcruz@uevora.pt (T.C.)

5 Departamento de Biologia, Escola de Ciências e Tecnologia, Universidade de Évora, 7002-554 Évora, Portugal

* Correspondence: baduarte@fc.ul.pt

check for

updates

Citation: Duarte, B.; Mamede, R.;

Duarte, I.A.; Caçador, I.; Tanner, S.E.; Silva, M.; Jacinto, D.; Cruz, T.;

Fonseca, V.F. Elemental

Chemometrics as Tools to Depict

Stalked Barnacle (Pollicipes pollicipes)

Harvest Locations and Food Safety.

Molecules 2022, 27, 1298. https://

doi.org/10.3390/molecules 27041298

Academic Editor: Daniel Cozzolino

Received: 27 January 2022

Accepted: 11 February 2022

Published: 15 February 2022

Publisher's Note: MDPI stays neutral with regard to jurisdictional claims in published maps and institutional affiliations.

Copyright: (C) 2022 by the authors. Licensee MDPI, Basel, Switzerland. This article is an open access article distributed under the terms and conditions of the Creative Commons Attribution (CC BY) license (https:// creativecommons.org/licenses/by/ $4.0 /)$.

\begin{abstract}
The stalked barnacle Pollicipes pollicipes is an abundant species on the very exposed rocky shore habitats of the Spanish and Portuguese coasts, constituting also an important economical resource, as a seafood item with high commercial value. Twenty-four elements were measured by untargeted total reflection X-ray fluorescence spectroscopy (TXRF) in the edible peduncle of stalked barnacles sampled in six sites along the Portuguese western coast, comprising a total of 90 individuals. The elemental profile of 90 individuals originated from several geographical sites ( $N=15$ per site), were analysed using several chemometric multivariate approaches (variable in importance partial least square discriminant analysis (VIP-PLS-DA), stepwise linear discriminant analysis (S-LDA), linear discriminant analysis (LDA), random forests (RF) and canonical analysis of principal components (CAP)), to evaluate the ability of each approach to trace the geographical origin of the animals collected. As a suspension feeder, this species introduces a high degree of background noise, leading to a comparatively lower classification of the chemometric approaches based on the complete elemental profile of the peduncle (canonical analysis of principal components and linear discriminant analysis). The application of variable selection approaches such as the VIP-PLS-DA and S-LDA significantly increased the classification accuracy (77.8\% and $84.4 \%$, respectively) of the samples according to their harvesting area, while reducing the number of elements needed for this classification, and thus the background noise. Moreover, the selected elements are similar to those selected by other random and non-random approaches, reinforcing the reliability of this selection. This untargeted analytical procedure also allowed to depict the degree of risk, in terms of human consumption of these animals, highlighting the geographical areas where these delicacies presented lower values for critical elements compared to the standard thresholds for human consumption.
\end{abstract}

Keywords: seafood; chemometrics; traceability; food safety; multi-elemental signature; barnacles

\section{Introduction}

Seafood is a key component of the human diet, with increasing demands nowadays [1]. In the last decades, seafood comprised about $16.7 \%$ of animal protein intake per capita, with a tendency to increase due to a higher concern with a healthier food regime (world per capita consumption on average in the 1960s: $9.9 \mathrm{~kg}$, and in 2013: $19.7 \mathrm{~kg}$ ) [1]. With higher demand, there is also an increased risk of seafood mislabelling, either unintentional or with 
the intent to gain profit from illegal practices [2]. Recent fisheries expansion and globalization, along with greater public awareness regarding food quality, led to a growing interest in several issues related to seafood authenticity and compliance with food legislation. As per the European Regulation No 1379/2013 [3] fishery and aquaculture products must be labelled with the commercial designation, species scientific name, production method (e.g., caught, farmed), fishing gear (e.g., hook, trap, trawl), and catch or production area. Errors in label information about seafood origin and production process are increasing in frequency to such an extent that seafood products are nowadays the second category of food most vulnerable to fraud [1]. The implementation of seafood labelling and traceability all over the world led to an increasing number of studies aiming to develop biochemical and elemental tags to provide unequivocal natural labels of the product capture or production, independently of the producer's information [4]. These tools comprise DNA barcoding techniques [5,6], fatty acid profiling [7,8], microbial profiling [9] and trace element fingerprinting or profiling [10-15]. Considering elemental profiling, total X-ray fluorescence (TXRF) spectroscopy has been pointed out as a high-throughput non-targeted analytical tool to efficiently quantify the elemental composition of seafood products, tracing the product geographical origin whilst simultaneously, if the targeted tissue is edible, providing accurate food safety values [13,16-18].

Barnacles are key organisms on rocky shores, being exploited as important economic resources, namely the giant barnacle Austromegabalanus psittacus in Chile, the acorn barnacle Megabalanus azoricus in Azores (Portugal) and the stalked barnacles of the genus Pollicipes [19]. Considering this last genus, all species are edible (P. polymerus, north-eastern Pacific Ocean, P. elegans, tropical eastern Pacific Ocean, P. caboverdensis, Cape Verde Islands and P. pollicipes, north-eastern Atlantic Ocean), but P. pollicipes can be considered the most important intertidal economical resource on rocky shores of North Spain and continental Portugal, with a commercial value ranging from EUR 20 to 200 per $\mathrm{kg}$ in restaurants [20]. In terms of species conservation, several legislations are enforced in Portugal aiming to establish limits for barnacle harvesting and geographical areas where this activity is allowed, either for professional or recreational harvesting [21-23]. Nevertheless, the identification of the harvesting sites is based on the information provided by the fishermen [21], and thus more prone to mislabelling events. Previous works [10] have identified the capitula elemental signatures as potential tracers for $P$. pollicipes harvesting origin, with an $87 \%$ success rate. Nevertheless, the capitula is not the edible part of the organism. Thus, an approach focusing on the edible peduncle would allow not only to develop traceability tools, based on chemometric approaches, but also provide a risk assessment of the edible parts for human consumption [13].

Accordingly, the present work aims to disclose the potential of TXRF-based nontargeted multi-elemental fingerprinting of $P$. pollicipes peduncle using several chemometric approaches for geographical origin traceability assessment, with simultaneous evaluation of food safety values related to the presence and concentration of potentially toxic elements. This represents a rather novel approach to the traceability of these high commercial-value organisms, not only due to the application of a non-targeted analytical tool (TXRF) but also due to the application of several chemometric approaches to the edible peduncle of P. pollicipes, in opposition to previous works that focused on the calcarean structures of these organisms [10].

\section{Results}

\subsection{Barnacle Peduncle Elemental Concentrations and Safety Values}

Arsenic concentrations in P. pollicipes peduncle ranged from 0 to $34.6 \mathrm{mg} / \mathrm{kg}$, with the lowest concentrations found in the individuals captured at the northern location, Viana do Castelo (Figure 1A). A similar pattern was found in the Br peduncle content, ranging in this case from 1.4-70.8 mg/kg (Figure 1B). Regarding Ca and Cl contents (Figure 1C,D, respectively), these were also found to be lower in the animals collected at Viana do Castelo, followed by P. pollicipes individuals collected at Matosinhos and Sagres, with 
the concentrations of these elements ranging from 47.6 to $3335.4 \mathrm{mg} / \mathrm{kg}$ and from 13.7 to $2877.0 \mathrm{mg} / \mathrm{kg}$ peduncle wet weight, respectively. As for potassium peduncle content (Figure 1E; ranging 9719.1 to $1138.3 \mathrm{mg} / \mathrm{kg}$ ), it was higher in individuals collected in both northern sampling areas (Viana do Castelo and Matosinhos) when compared to the lowest values observed in the animals harvested at the southern locations (Sines and Sagres). The lowest sodium contents $(1218.1 \mathrm{mg} / \mathrm{kg}$ ) were found in individuals captured at Viana do Castelo, while the animals from Ericeira and Sines exhibited the highest contents of this element (maximum $=9220.7 \mathrm{mg} / \mathrm{kg}$ ) (Figure 1F). Phosphorous peduncle contents ranged from 437.0 to $3686.4 \mathrm{mg} / \mathrm{kg}$ and were found to have their lowest values in the individuals collected at Sines, Sagres and Ericeira (Figure 1G). Praseodymium showed a highly conservative behaviour along the barnacle populations surveyed, with no significant differences observed between the sampling sites and ranging from 0 to $4.7 \mathrm{mg} / \mathrm{kg}$ (Figure 1H). Rubidium peduncle content (Figure 1I) was also found to be very stable along the sampling gradient with lower values detected in the animals collected at Viana do Castelo, Matosinhos, Sines and Sagres, when compared to the ones harvested at Ericeira and Cabo Raso (ranging from 0 to $7.8 \mathrm{mg} / \mathrm{kg}$ ). Ruthenium peduncle content was very stable along the individuals surveyed from all sampling sites, ranging from 0 to $73.8 \mathrm{mg} / \mathrm{kg}$ (Figure 1J). Sulphur content in the peduncle tissues of the surveyed barnacles (Figure $1 \mathrm{~K}$ ), was found to be rather stable along the surveyed areas, with significantly lower contents in the animals collected at Viana do Castelo (overall range $=769.6$ to $7331.4 \mathrm{mg} / \mathrm{kg}$ ) Selenium peduncle content (Figure 1L) was found to be lowest in the animals captured at Sines and Viana do Castelo (minimum value $=0.16 \mathrm{mg} / \mathrm{kg}$ ), while the individuals harvested at Matosinhos and Ericeira showed the higher values of this element (maximum value $=0.74 \mathrm{mg} / \mathrm{kg}$ ). Samarium peduncle contents (Figure $1 \mathrm{M}$ ) showed higher values in the animals harvested at Viana do Castelo and Matosinhos, while the remaining surveyed areas showed significantly lower values (overall ranging from 0 to $3.0 \mathrm{mg} / \mathrm{kg}$ ). Similar to what was found for other elements, strontium values were also found to have lower values in the animals captured at Viana do Castelo (minimum value $=0.12 \mathrm{mg} / \mathrm{kg}$ ), being very similar in the animals collected at the remaining sampling sites, ranging to a maximum of $83.1 \mathrm{mg} \mathrm{Sr} / \mathrm{kg}$ detected in the individuals collected at Cabo Raso (Figure 1N). Regarding titanium and yttrium peduncle contents no significant differences could be observed among the individuals collected at the six surveyed sites (Figures $1 \mathrm{O}$ and $1 \mathrm{Q}$, respectively). Lastly, vanadium peduncle contents (Figure 1P) showed the highest values in the individuals collected at Cabo Raso and Sines (maximum value $=1.0 \mathrm{mg} / \mathrm{kg}$ ), being this element present in very low concentrations in the individuals collected at the remaining sampling sites.

The animals harvested at Viana do Castelo and Matosinhos showed the lowest peduncle concentrations of $\mathrm{Cr}$. Maximum values of this element were detected in the samples collected at Ericeira, Sines and Sagres ( $\mathrm{Cr}$ concentration range: $0-2 \mathrm{mg} / \mathrm{kg}$ ) (Supplementary Table S1). Nevertheless, and considering the international guidelines thresholds for this element $(15 \mathrm{mg} / \mathrm{kg} \mathrm{ww})$, all the analysed samples showed safe values which concerns $\mathrm{Cr}$ concentration (Figure 2A, ratio bellow 1). Copper values ranged from 0.15 to $1.8 \mathrm{mg} / \mathrm{kg}$, being the lowest values observed in the animals captured at Viana do Castelo and Matosinhos, and the highest at Ericeira and Cabo Raso (Supplementary Table S1). Again, none of the samples surpassed the safety thresholds for human consumption regarding this element (Figure 2B, ratio bellow 1). Regarding the Fe peduncle contents, except for samples collected at Matosinhos, all sampling sites exhibited individuals with iron contents above the recommended thresholds for human consumption (Figure 2C). To be more precise, 42 barnacle samples ( $47 \%$ ) surpassed the $43 \mathrm{mg} / \mathrm{kg}$ threshold (ratio above 1). The iron values in the surveyed samples ranged from 2.4 to $211.4 \mathrm{mg} / \mathrm{kg}$, with the highest Fe values detected in the samples collected at Ericeira, Cabo Raso and Sagres (Supplementary Table S1). About 70\% of the samples surpassed the regulatory $\mathrm{Mn}$ threshold of $1 \mathrm{mg} / \mathrm{kg}$ (Figure 2D), with Mn concentrations ranging from 0 to $9.3 \mathrm{mg} / \mathrm{kg}$ over the surveyed sites (Supplementary Table S1). The lowest values of this element were detected in the peduncle of the animals captured at Matosinhos, while no signifi- 
cant differences could be observed among the animals collected at the remaining sites. Nickel values $(0-0.9 \mathrm{mg} / \mathrm{kg}$, Supplementary Table S1) were found to be below the regulatory thresholds $(80 \mathrm{mg} / \mathrm{kg})$, with minimum values assessed for the individuals collected at Viana do Castelo and maximum values in the animals captured at Ericeira, Sines and Sagres (Figure 2E). Lead concentration regulatory thresholds $(1 \mathrm{mg} / \mathrm{kg})$ was surpassed in 30\% of the barnacle samples (Figure 2F). Only the samples collected at Viana do Castelo were below this threshold value, being significantly lower than the observed in individuals harvested at Ericeira, Cabo Raso, Sines (maximum detected values of $14.9 \mathrm{mg} / \mathrm{kg}$ ) and Sagres (Supplementary Table S1). Regarding Zn peduncle concentrations (Supplementary Table S1) these were found to be minimum in the animals collected at Viana do Castelo and Matosinhos (minimum value $=3.5 \mathrm{mg} / \mathrm{kg}$ ), being this also the only site where none of the samples surpassed the regulatory $40 \mathrm{mg} / \mathrm{kg}$ threshold (Figure 2G). Maximum $\mathrm{Zn}$ values $(571.0 \mathrm{mg} / \mathrm{kg}$ ) were detected in the samples collected at Ericeira and Cabo Raso. Accordingly, $76 \%$ of the samples surpassed the $\mathrm{Zn}$ regulatory thresholds for human consumption.
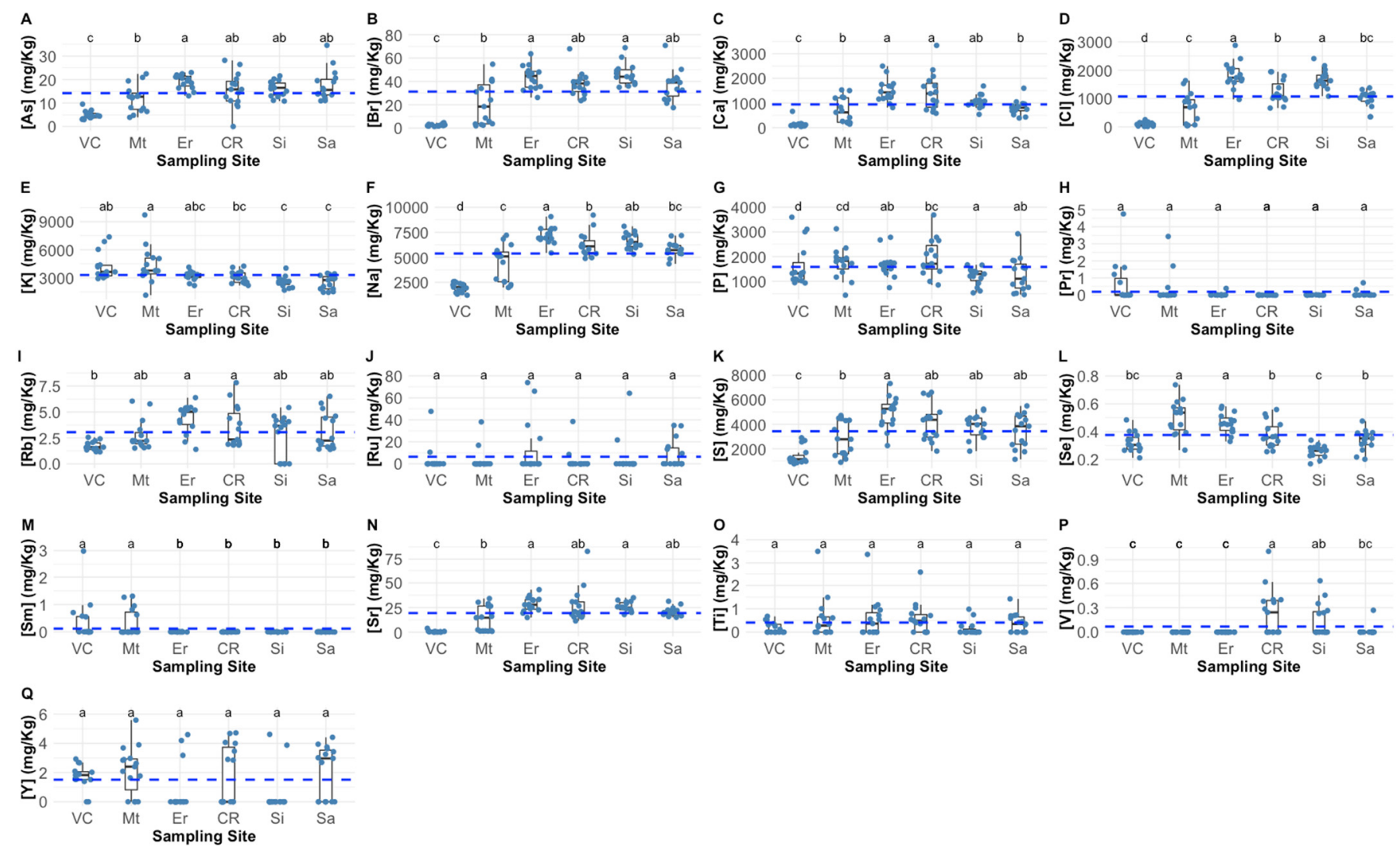

Figure 1. Arsenic, (A), bromine (B), calcium (C), chlorine (D), potassium (E), sodium (F), phosphorous $(\mathbf{G})$, praseodymium $(\mathbf{H})$, rubidium $(\mathbf{I})$, ruthenium $(\mathbf{J})$, sulphur $(\mathbf{K})$, selenium $(\mathbf{L})$, samarium $(\mathbf{M})$, strontium $(\mathbf{N})$, titanium $(\mathbf{O})$, vanadium $(\mathbf{P})$ and yttrium $(\mathbf{Q})$ Pollicipes pollicipes peduncle concentrations (wet weight) of the individuals collected at the six sampling sites (VC-Viana do Castel; Mt - Matosinhos; Er-Ericeira; CR-Cabo Raso; Si-Sines; Sa-Sagres; dotted blue lines represent the average value detected for the whole dataset). Statistical letters denote significant differences between sampling sites at $p<0.05$. 

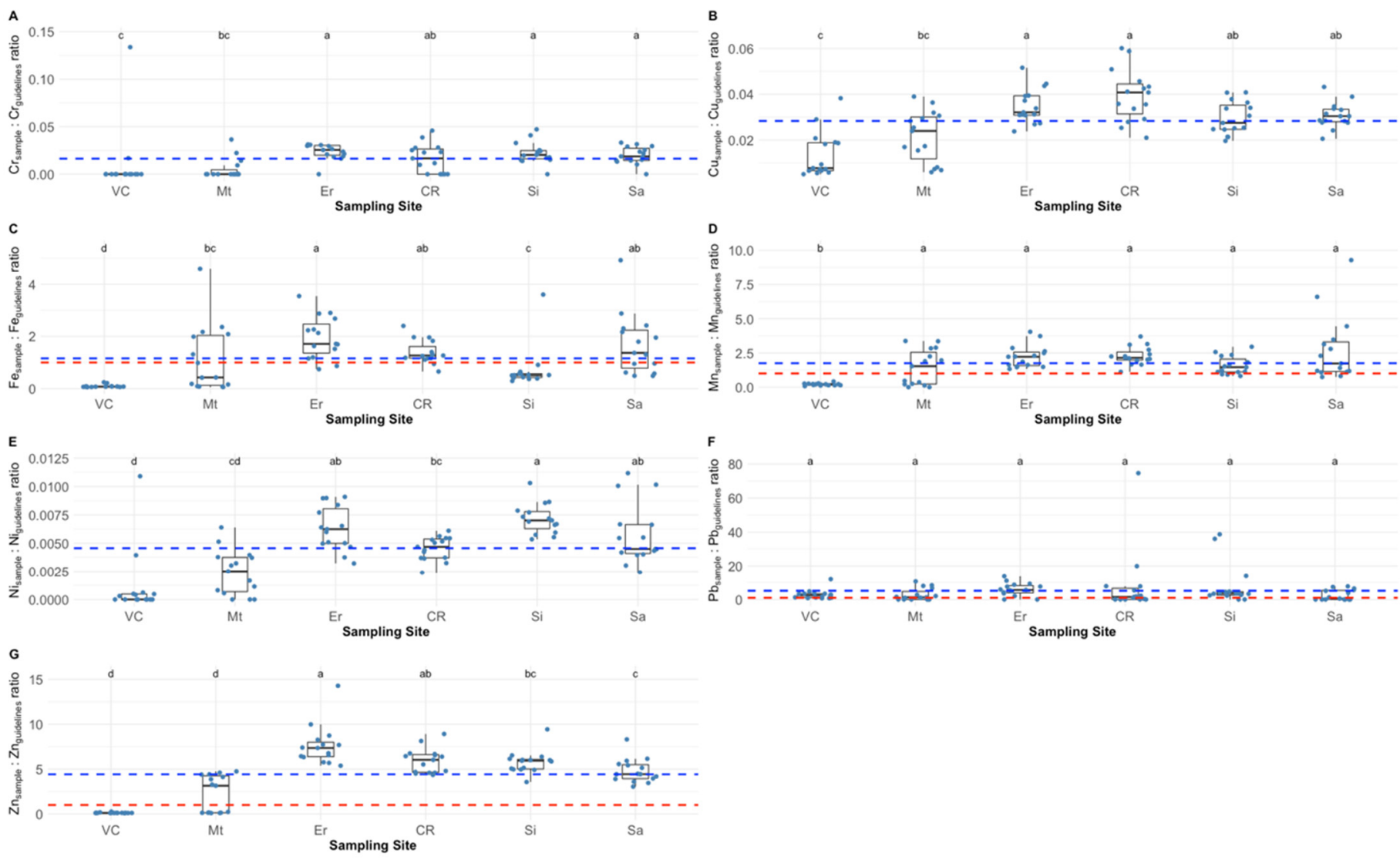

Figure 2. Chromium, (A), copper (B), iron (C), manganese (D), nickel (E), lead (F) and zinc (G) ratios between the measured values and the international thresholds in Pollicipes pollicipes peduncle, of the individuals collected at the six sampling sites (VC-Viana do Castelo; Mt-Matosinhos; Er-Ericeira; CR-Cabo Raso; Si-Sines; Sa-Sagres; dotted blue lines represent the average value detected for the whole dataset; the dotted red line represents the safety threshold ratio (ratio =1) according to international regulatory authorities; for $\mathrm{Cr}, \mathrm{Cu}$ and $\mathrm{Ni}$ the international threshold guidelines are far above the results attained from this study samples and thus the correspondent dotted red lines were are not displayed). Statistical letters denote significant differences between sampling sites at $p<0.05$.

Analysing the concentration trends of the detected elements (Figure 3), it can be observed that most of the elements show significant and positive correlations between them, with only a few exceptions such as potassium, praseodymium and samarium. These show a large number of inverse significant correlations with the remaining analysed elements. This introduces a high degree of multicollinearity, that will latterly be discussed in terms of the chemometric approach.

\subsection{Chemometric Provenance Classification}

Several multivariate statistical analyses were used as chemometric tools to depict the geographical elemental signatures of the animals harvested in the different locations. For visualization purposes, the resulting plots from the LDA, CAP, PLS-DA and RF analyses are presented in Figure 4. In all projections, the same pattern is observed with three geographical groups or areas formed by distinct sampling sites: (i) a northern area composed of the samples collected at Viana do Castelo and Matosinhos; (ii) a central area gathering the samples harvested at Ericeira and Cabo Raso and (iii) a southern area composed by the samples collected at Sines and Sagres. Observing the confusion matrixes (Table 1) from the different tested chemometric approaches it is also possible to observe that most of the misclassification events occur within these three groups. In terms of models' accuracy, the stepwise linear discriminant analysis (S-LDA) showed the highest accuracy in classifying 
the samples correctly according to their geographical origin (84.4\%), based on the elemental concentrations of As, Se, Ca, Fe, Zn, V, Ni, P and Sm as descriptors. This is an evident improvement in comparison with the use of the whole elemental dataset within a similar technique, as observed in the accuracy results (72.7\%) for the stepwise linear discriminant analysis (LDA). Comparing the results from the partial least-squares discriminant analysis (PLS-DA) and the variable importance in projection partial least-squares discriminant analysis (VIP-PLS-DA), no improvements in terms of classification accuracy could be observed (77.8\% accuracy in both methods, Table 1$)$. In this last model, only the variables with a variable importance in projection (VIP) score above 1 were considered (in this case $\mathrm{Br}, \mathrm{Ca}$, $\mathrm{Cl}, \mathrm{Fe}, \mathrm{K}, \mathrm{Na}, \mathrm{Ni}, \mathrm{S}, \mathrm{Se}, \mathrm{Sr}$ and $\mathrm{Zn}$ ). Canonical analysis of principal (CAP) components and random forest (RF) analysis had the lowest classification accuracy of $73.3 \%$ and $70 \%$, respectively. In terms of sensitivity, S-LDA showed the highest sensitivity and specificity, followed by both PLS-DA approaches (PLS-DA and VIP-PLS-DA).

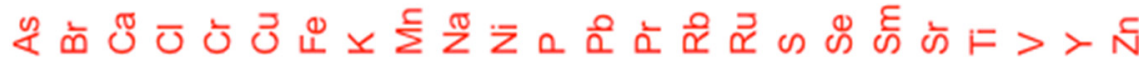

As

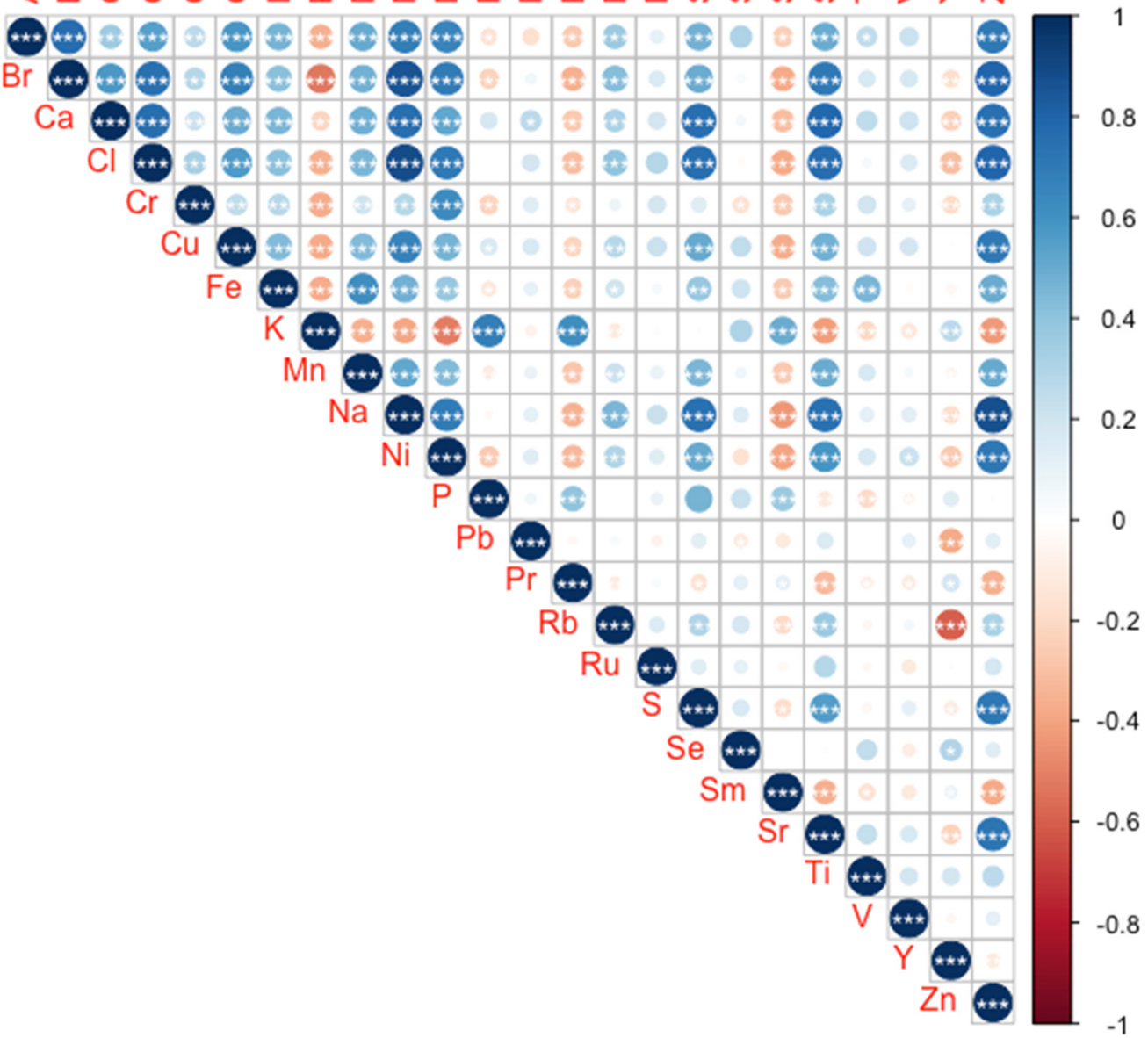

Figure 3. Spearman correlation matrix heatmap $(\varrho)$ between the elemental concentrations detected in Pollicipes pollicipes peduncle (asterisks denote significant correlations at $p<0.05^{*}, p<0.01{ }^{* *}$ and $\left.p<0.001^{* * *}\right)$.

Analysing the element relative weight for models' accuracy and sample geographical classification, there were some consistent patterns among the tested chemometric approaches (Figure 5). Selenium is one of the most relevant elements for correct sample classification in all the tested approaches. Sodium also presented relevant importance for the classification accuracy of four models, with the exception of the LDA (Figure 5C) and S-LDA (Figure 5D) approaches. Apart from the S-LDA approach, Ni also showed a high degree of importance in the remaining chemometric models applied. Calcium and $\mathrm{Zn}$ showed a preponderant role to achieve high accuracy classifications when applying RF and 
CAP methodologies (Figure 5E,F). Arsenic was found to be highly relevant for achieving the high accuracy values observed in the S-LDA approach. Regarding the remaining elements analysed, these were found to have very similar weights within the variables tested in the different tested approaches.

A
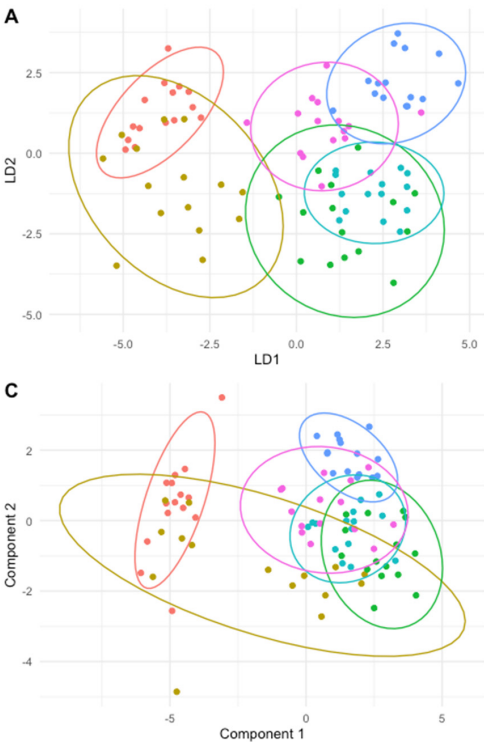
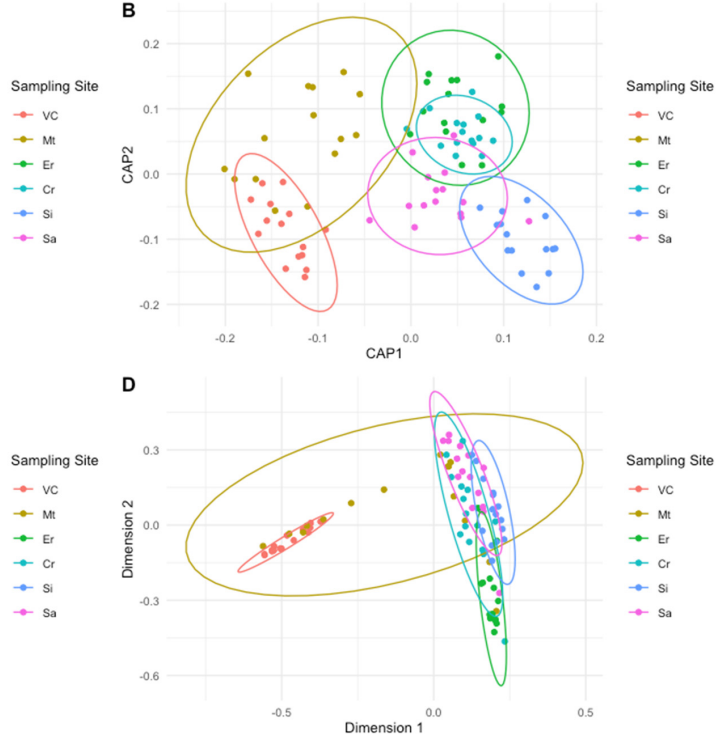

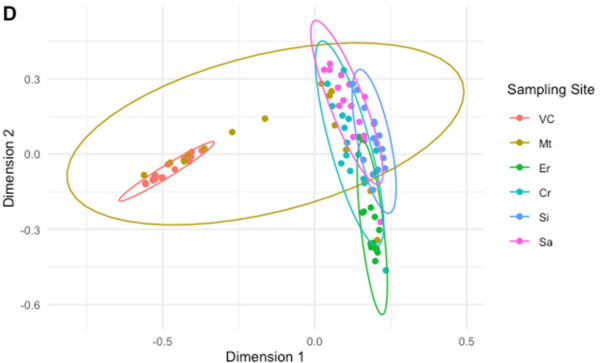

Figure 4. Linear discriminant analysis (LDA, A), canonical analysis of principal components (CAP, B), partial least-squares discriminant analysis (PLS-DA, C) and random forests (RF, D) projection plots of the Pollicipes pollicipes peduncle elemental profiles, from the individuals collected at Viana do Castelo (VC), Matosinhos (Mt), Ericeira (Er), Cabo Raso (Cr), Sines (Si) and Sagres (Sa) sampling sites.

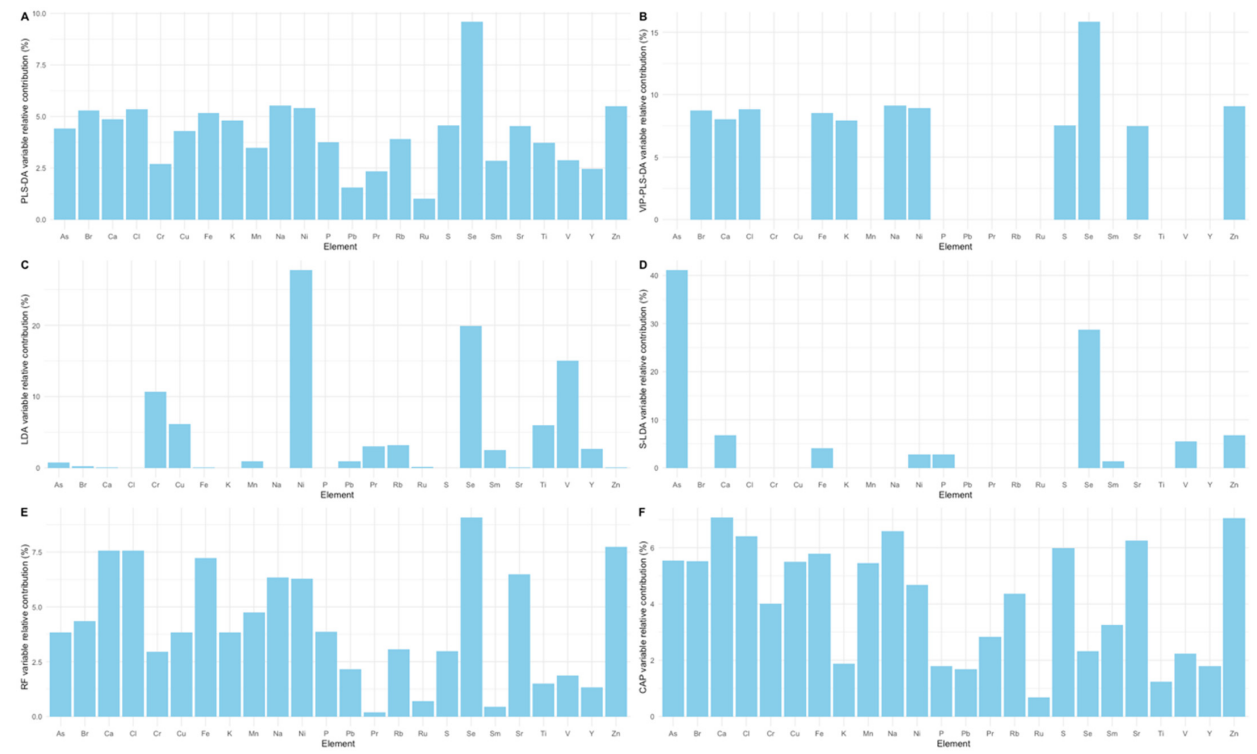

Figure 5. Element variable relative contribution in each of the chemometric models tested: Partial least-squares discriminant analysis (PLS-DA, A), variable importance in projection partial leastsquares discriminant analysis (VIP-PLS-DA, B), linear discriminant analysis (LDA, C), stepwise linear discriminant analysis (S-LDA, D), random forests (RF, E) and canonical analysis of principal coordinates (CAP, F). 
Table 1. Partial least-squares discriminant analysis (PLS-DA), variable importance in projection partial least-squares discriminant analysis (VIP-PLS-DA), linear discriminant analysis (LDA), stepwise linear discriminant analysis (S-LDA), random forests (RF) and canonical analysis of principal coordinates (CAP) confusion matrixes (correctly classified samples in bold) and model performance traits (overall model accuracy and group classification accuracy, precision, sensitivity and specificity), based on the elemental profiles of the individuals collected at Viana do Castelo (VC), Matosinhos (Mt), Ericeira (Er), Cabo Raso (Cr), Sines (Si) and Sagres (Sa) sampling sites.

\begin{tabular}{|c|c|c|c|c|c|c|c|c|c|c|c|c|}
\hline \multirow[b]{2}{*}{ Model } & \multirow[b]{2}{*}{ Origin } & \multicolumn{6}{|c|}{ Predicted } & \multirow{2}{*}{$\begin{array}{c}\text { Overall } \\
\text { Accuracy } \\
(\%)\end{array}$} & \multirow{2}{*}{ Accuracy (\%) } & \multirow{2}{*}{ Precision (\%) } & \multirow{2}{*}{ Sensitivity (\%) } & \multirow{2}{*}{ Specificity (\%) } \\
\hline & & VC & Mt & Er & $\mathrm{CR}$ & $\mathrm{Si}$ & Sa & & & & & \\
\hline \multirow{6}{*}{ PLS-DA } & VC & 14 & 1 & 0 & 0 & 0 & 0 & \multirow{6}{*}{77.8} & 90.9 & 70.0 & 93.3 & 90.3 \\
\hline & Mt & 6 & 6 & 2 & 0 & 0 & 1 & & 85.4 & 66.7 & 40.0 & 95.5 \\
\hline & Er & 0 & 0 & 14 & 0 & 0 & 1 & & 90.9 & 70.0 & 93.3 & 90.3 \\
\hline & CR & 0 & 2 & 1 & 11 & 1 & 1 & & 93.3 & 91.7 & 73.3 & 98.3 \\
\hline & $\mathrm{Si}$ & 0 & 0 & 0 & 0 & 15 & 0 & & 98.6 & 93.8 & 100.0 & 98.2 \\
\hline & Sa & 0 & 2 & 1 & 1 & 1 & 10 & & 89.7 & 76.9 & 66.7 & 95.2 \\
\hline \multirow{6}{*}{ VIP-PLS-DA } & VC & 14 & 1 & 0 & 0 & 0 & 0 & \multirow{6}{*}{77.8} & 90.9 & 70.0 & 93.3 & 90.3 \\
\hline & Mt & 5 & 10 & 0 & 0 & 0 & 0 & & 88.6 & 71.4 & 66.7 & 93.8 \\
\hline & Er & 0 & 0 & 13 & 0 & 1 & 1 & & 94.6 & 86.7 & 86.7 & 96.6 \\
\hline & CR & 0 & 3 & 1 & 8 & 1 & 2 & & 89.7 & 88.9 & 53.3 & 98.4 \\
\hline & $\mathrm{Si}$ & 0 & 0 & 1 & 0 & 14 & 0 & & 93.33 & 77.78 & 93.33 & 93.33 \\
\hline & Sa & 1 & 0 & 0 & 1 & 2 & 11 & & 90.9 & 78.6 & 73.3 & 95.2 \\
\hline \multirow{6}{*}{$\begin{array}{c}\text { LDA } \\
\text { (validation set) }\end{array}$} & $\mathrm{VC}$ & 3 & 0 & 0 & 0 & 0 & 0 & \multirow{6}{*}{72.7} & 91.4 & 50.0 & 100.0 & 90.6 \\
\hline & Mt & 1 & 4 & 0 & 0 & 0 & 0 & & 97.0 & 100.0 & 80.0 & 100.0 \\
\hline & $\mathrm{Er}$ & 0 & 0 & 6 & 2 & 0 & 2 & & 84.2 & 75.0 & 60.0 & 92.9 \\
\hline & CR & 2 & 0 & 1 & 7 & 0 & 1 & & 84.2 & 77.8 & 63.6 & 92.6 \\
\hline & $\mathrm{Si}$ & 0 & 0 & 1 & 0 & 7 & 1 & & 91.4 & 87.5 & 77.8 & 96.2 \\
\hline & Sa & 0 & 0 & 0 & 0 & 1 & 5 & & 86.5 & 55.6 & 83.3 & 87.1 \\
\hline \multirow{6}{*}{ S-LDA } & VC & 14 & 1 & 0 & 0 & 0 & 0 & \multirow{6}{*}{84.4} & 93.8 & 77.8 & 93.3 & 93.9 \\
\hline & $\mathrm{Mt}$ & 4 & 11 & 0 & 0 & 0 & 0 & & 93.8 & 91.6 & 73.3 & 98.5 \\
\hline & Er & 0 & 0 & 14 & 0 & 1 & 0 & & 93.8 & 77.8 & 93.3 & 93.9 \\
\hline & $\mathrm{CR}$ & 0 & 0 & 3 & 11 & 0 & 1 & & 93.8 & 91.6 & 73.3 & 98.5 \\
\hline & $\mathrm{Si}$ & 0 & 0 & 0 & 0 & 14 & 1 & & 96.2 & 87.4 & 93.3 & 96.9 \\
\hline & Sa & 0 & 0 & 1 & 1 & 1 & 12 & & 93.8 & 85.7 & 79.9 & 97.0 \\
\hline \multirow{6}{*}{ RF } & VC & 12 & 3 & 0 & 0 & 0 & 0 & \multirow{6}{*}{70.0} & 92.6 & 85.7 & 80.0 & 96.2 \\
\hline & $\mathrm{Mt}$ & 2 & 10 & 2 & 0 & 0 & 1 & & 87.5 & 71.4 & 66.7 & 93.0 \\
\hline & Er & 0 & 0 & 12 & 0 & 1 & 2 & & 88.7 & 70.6 & 80.0 & 91.1 \\
\hline & $\mathrm{CR}$ & 0 & 1 & 2 & 8 & 2 & 2 & & 86.3 & 72.7 & 53.3 & 94.8 \\
\hline & $\mathrm{Si}$ & 0 & 0 & 0 & 0 & 13 & 2 & & 88.7 & 68.4 & 86.7 & 89.3 \\
\hline & $\mathrm{Sa}$ & 0 & 0 & 1 & 3 & 3 & 8 & & 81.8 & 53.3 & 53.3 & 88.7 \\
\hline \multirow{6}{*}{ CAP } & VC & 11 & 3 & 0 & 0 & 0 & 1 & \multirow{6}{*}{73.3} & 88.0 & 68.8 & 73.3 & 91.7 \\
\hline & $\mathrm{Mt}$ & 4 & 10 & 1 & 0 & 0 & 0 & & 88.0 & 71.4 & 66.7 & 93.3 \\
\hline & Er & 0 & 0 & 12 & 1 & 1 & 1 & & 89.2 & 70.6 & 80.0 & 91.5 \\
\hline & CR & 0 & 1 & 2 & 11 & 0 & 1 & & 89.2 & 73.3 & 73.3 & 93.2 \\
\hline & $\mathrm{Si}$ & 0 & 0 & 0 & 2 & 12 & 1 & & 93.0 & 85.7 & 80.0 & 96.4 \\
\hline & $\mathrm{Sa}$ & 1 & 0 & 2 & 1 & 1 & 10 & & 88.0 & 71.4 & 66.7 & 93.3 \\
\hline
\end{tabular}

\section{Discussion}

Animal tissues elemental composition is intrinsically linked to the chemical composition of their environment, but it is also modulated by the animal physiology and food sources intake [24-26]. To our knowledge, the elemental signature of barnacles' edible peduncle has not been used for geographical traceability purposes, with only one study focusing on P. pollicipes calcified capitula structures for this purpose [10]. Given that $P$. pollicipes is considered the most important intertidal economical resource on rocky shores of North Spain and continental Portugal, due to their high commercial value [27], the need to develop tools that allow tracing the harvesting site of the commercialized barnacles is greatly increased. Additionally, if this approach can simultaneously focus on the geographical provenance of the product while evaluating its food safety requirements for human consumption, its relevance is reinforced.

Since there is no specific information available in the literature concerning the best elemental data set to discriminate the geographical origin of $P$. pollicipes based on its edible peduncle, the first chemometric analysis focused on all the 24 elements measured, by exploring the data employing LDA and CAP are reported in the present study. The accuracy of both approaches was not the highest among the tested models. The high multicollinearity between elemental variables as well as geographical-unrelated variability 
is often considered a source of increasing noise, thus reducing the maximum accuracy of whole dataset based models [28]. This was also observed in the present study, with a high number of elements presenting significant correlations between each other, increasing the multicollinearity of the dataset. The main significant patterns of covariations were found among between $\mathrm{Zn}$ and $\mathrm{Na}$ and, in particular, between the halogens $\mathrm{Br}$ and $\mathrm{Cl}(\varrho>0.78)$, followed by correlations between $\mathrm{Na}, \mathrm{Zn}, \mathrm{Br}, \mathrm{Sr}$ and $\mathrm{Ni}(\varrho>0.70)$. These are not only the most abundant elements in marine water, but the concentration of these elements in seawater is rather conservative, exhibiting very low variation [29]. Due to their filter and captorial feeding habits, barnacles not only capture preys with their cirri [30] but also filtrate seawater, and thus the high abundance of these elements allied to the common uptake rates supports the high multicollinearity observed. This might explain the high concentration of these elements measured in the barnacles' peduncles. On the opposite end, praseodymium, samarium and yttrium concentrations in the barnacles' peduncles showed several inverse correlations with most of the analysed elements. These elements are among the less abundant (yttrium is in fact considered a Rare Earth Element, REE), not only in seawater but also in the whole planet, thus suggesting a different uptake process from the highly abundant elements. Moreover, these elements show a similar accumulation behaviour to the observed for K, with inverse correlations with Na. Marine organisms live in a medium with an inexhaustible supply of $\mathrm{K}$, being the uptake of these elements often intrinsically regulated by antiport systems [31]. In the case of praseodymium, samarium and yttrium, their rare character indicates that their uptake mechanism is not the same as for $\mathrm{K}$, but the results here presented point to possible co-transport systems.

Thus, the reduction of explanatory variables is often an efficient way to reduce this background noise, especially given a future practical implementation of the methodology. Variable selection is highly dependent on the sample matrix properties as well as on the dataset overall characteristics [28]. Particularly, in the case of seafood samples, this is highly dependent on the animals feeding, moving and ecological traits, as well as the variability of the marine habitats, that overall affect the animal element uptake [24-26] and thus the selected variables. This points to a case-specific selection of variables and not to a transversal elemental selection, independently of the samples. For these purpose, two approaches based on variable selection were undertaken VIP-PLS-DA and S-LDA. The latter presented the highest degree of accuracy, as well as of all the other model performance metrics considered, namely precision, sensitivity and specificity.

Akin to the CAP analyses, S-LDA is probably the most frequently used classification technique when dealing with elemental profiling data [28]. Some critics of this approach are due to the randomness of the variable selection, rather than an effective significance of the variables extracted [32]. Nevertheless, if this approach is compared with other variable selection models with a high degree of randomness (like Random Forests) and with a low degree of randomness, such as VIP-PLS-DA, some conclusions on the selected variables can be drawn, especially for those commonly selected among random and non-random approaches. In terms of variable selection, VIP-PLS-DA consists of a more robust and flexible algorithm, particularly fit for the classification of a large number of samples, and is recommended as a more powerful tool for reliable variable selection compared to SLDA [33]. Although some studies point to some disadvantages of PLS-DA, when used alone (for e.g., problems of overfitting and PLS scores plots), this integration of VIPS-PLSDA within a full classification procedure is advised [34]. In fact, as discussed below, several of the selected variables, as key drivers of the PLS-DA grouping, were simultaneously highlighted by the remaining chemometric approaches tested, reinforcing its integrated use along with other multivariate approaches [34].

Comparing the elements selected by the VIP-PLS-DA (VIP score $>1$ ) with the elements selected by the S-LDA, it was possible to observe that from the 8 elements selected in the latter (As, Se, Zn, Ca, V, Fe, Ni and P), 63\% (Se, Zn, Ca, Fe and Ni) were also selected by the VIP-PLS-DA, a method with a lower degree of randomness [33]. Even when comparing the VIP-PLS-DA most relevant elements with a random approach, such as the one provided 
by random forests, it is possible to observe that the eight most important variables (Se, $\mathrm{Zn}, \mathrm{Ca}, \mathrm{Cl}, \mathrm{Fe}, \mathrm{Sr}, \mathrm{Na}$ and $\mathrm{Ni}$ ) are common in both approaches. Comparing RF with SLDA, several elements are also common to both approaches considering the most relevant elements for the high accuracy values observed (Se, $\mathrm{Zn}, \mathrm{Ca}, \mathrm{Fe}$ and $\mathrm{Ni}$ ). These facts point to a reliable selection of variables obtained by the S-LDA approach, which in the present study gathered the highest degree of accuracy [33]. Among these elements are not only highly abundant elements, such as $\mathrm{Zn}, \mathrm{Ca}, \mathrm{Fe}$ and $\mathrm{P}$ but are also elements whose concentrations in the environment and in the barnacle tissues are far lower (As, Se, V and $\mathrm{Ni}$ ), excluding any environmental prevalence effect on the variable importance to the overall method accuracy. Comparing to previous traceability works focusing on this species [10], the selected elements by the presented chemometric approaches differ greatly. Albuquerque et al. (2016) used the calcified capitula as an analytical matrix, which revealed that $\mathrm{Ba}, \mathrm{B}, \mathrm{Cd}, \mathrm{Cr}, \mathrm{Li}, \mathrm{Mg}, \mathrm{Mn}, \mathrm{P}, \mathrm{Pb}, \mathrm{Sr}$ and $\mathrm{Zn}$ were the most important elements for discriminating the individuals' sampling areas. This is likely due to the different analytical techniques (ICP-MS versus TXRF) and choice of matrix (capitula versus edible soft tissues), as previously observed for other organisms using calcified structures [35]. Notably, some of the observed variability within sites (resulting in a cluster dispersion in LDA and CAP plot in some groups), can be due to different reproductive stages of the individuals (differing stages of ovarium development within the edible peduncle) [36], since collection was performed during the reproductive season. Another potential influencing factor is the small-scale variation of the habitat in which the animals were collected, as it was previously observed for this species using the calcified capitula [10] as well as for other organisms and their calcified structures [15].

By comparison to other seafood products and their elemental profiles available in the literature, some of the most discriminant elements found in the present study might be linked to anthropogenic pollution (As, Se, V, Ni) $[13,28,37]$. Both the individual element concentrations in the barnacle peduncle and the multivariate projections (LDA and CAP) seem to indicate three distinct geographical groups or areas (north, centre and south), that can be attributed to a latitudinal seawater chemical gradient alongside different degrees of anthropogenic pressures [38]. Moreover, these elemental accumulation patterns are in line with previous studies with the stalked barnacle P. pollicipes along the Portuguese coast $[39,40]$. In these previous works, the results for some of the legislated elements were also found to be above the international thresholds for human consumption, and in some cases with values above the ones here reported $[39,40]$. Nevertheless, it should be taken into account that only for $\mathrm{Pb}$, these thresholds are differentially established for crustaceans and fishes. For the remaining elements, a unique threshold for seafood is available, without taking into account the normally higher value present in deposit and suspension feeder organisms, thus leading to several samples from the present study being above the recommended threshold for human consumption. Additionally, in Portugal, stalked barnacles are generally not consumed as the main dish, and thus, it is not expectable to constitute a large portion of the daily intake food amount. In this way, the risks inherent to barnacle consumption are reduced considering the above threshold concentration values, observed for some elements and some barnacle populations along the Portuguese coast.

The application of untargeted X-ray fluorescence spectroscopy analysis has been growing for traceability studies based on elemental fingerprinting $[13,17,18]$, producing high-throughput results and a large number of elements, analysed with minimum sample preparation [41]. In the present study, this high-throughput dataset appears also to be suitable for chemometric approaches with a simultaneous evaluation of the food safety risk of stalked barnacles, being, therefore, a promising technique, equally efficient when compared to the more classic targeted techniques, such as inductively coupled plasmabased (ICP-MS) analysis. 


\section{Materials and Methods}

\subsection{Sample Collection}

Stalked barnacles (Pollicipes pollicipes) were collected in six rocky shore sites, along the Western Portuguese coast (Figure 6), in July and August 2021. A total of 90 P. pollicipes individuals were collected in all sampling areas. Individuals were transported fresh to the laboratory. For morphometry purposes, 15 individuals per site were weighed (mean \pm standard deviation, $3.9 \pm 1.6 \mathrm{~g}$ ) and their total height (mean \pm standard deviation, $45.9 \pm 11.6 \mathrm{~mm}$ ) measured. No significant differences were observed among sites for both weight and height $(p>0.05)$. After all morphometric measurements, the individuals were dissected by separating the edible part of the peduncle from the rest of the organism, by removing the outer cuticle. Peduncle samples were freeze-dried and stored at $-80{ }^{\circ} \mathrm{C}$ until further processing.

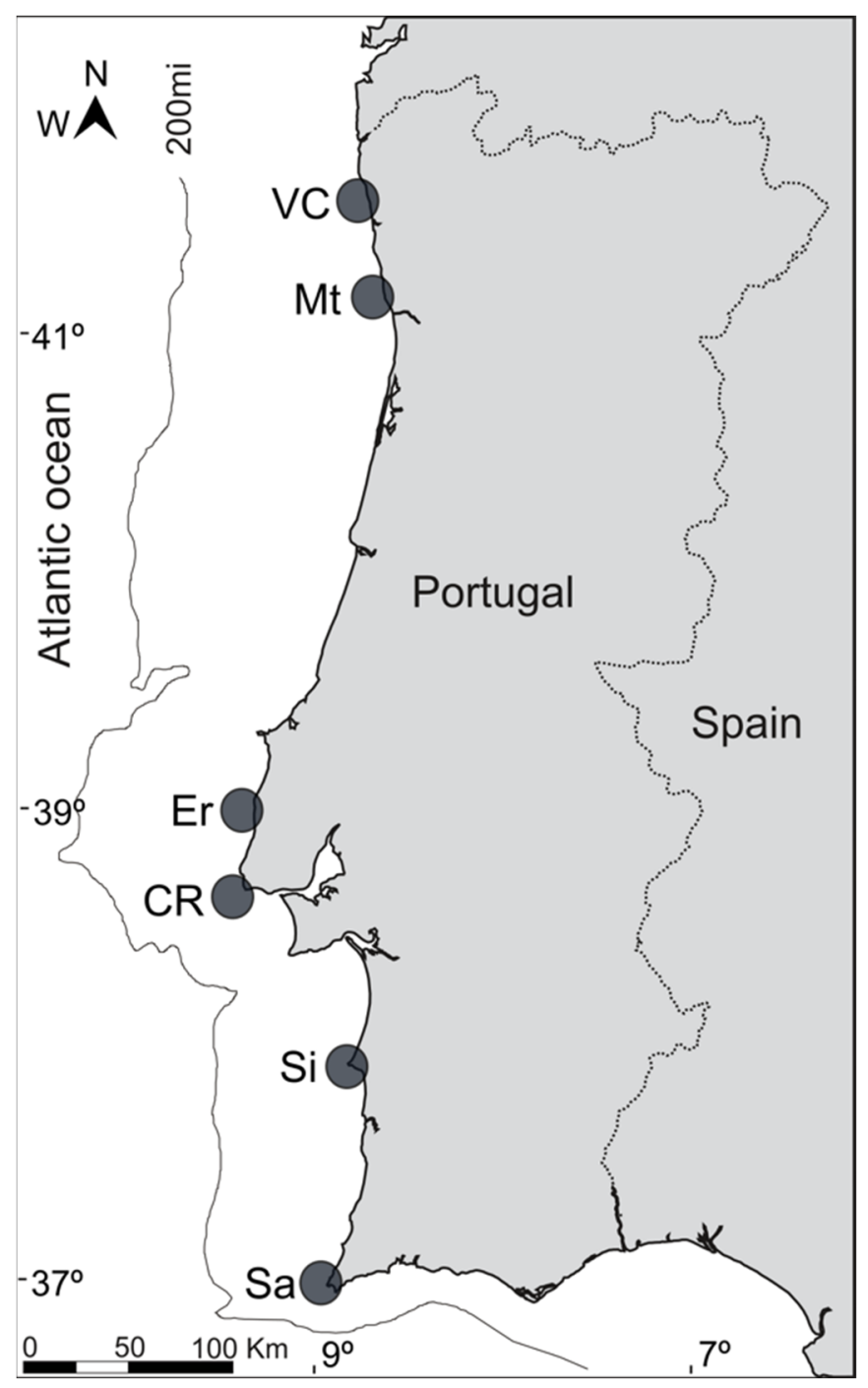

Figure 6. Location of the sampling sites of the specimens evaluated in the present study along the Portuguese Western coast (VC—Viana do Castelo; Mt-Matosinhos; Er-Ericeira; CR—Cabo Raso; Si-Sines; Sa-Sagres).

\subsection{Total Elemental Fingerprinting}

All labware used for elemental analysis were decontaminated in acid baths for $48 \mathrm{~h}$ before use. Freeze-dried samples (15 replicates per site) were mineralized with $\mathrm{HNO}_{3}$ in Teflon reactors, following a microwave digestion process (Multiwave GO, Anton Paar $\mathrm{GmbH}, \mathrm{Graz}$, Austria) according to the EPA 3052 method [42]. After cooling, an internal 
standard (Gallium) was added to each sample, and $5 \mu \mathrm{L}$ of each sample was then applied to a siliconized quartz disk (BruckerNano, Germany) and dried. Elemental concentrations (As, Br, Ca, Cl, Cr, Cu, Fe, K, Mn, Na, Ni, P, Pb, Pr, Rb, Ru, S, Se, Sm, Sr, Ti, V, Y, Zn) were determined by total reflection $X$-ray fluorescence spectroscopy (TXRF S2 PICOFOX, Brucker, Germany). Instrumental recalibration (gain correction, sensitivity analysis and multi-elemental standards) and analytical blanks were used for quality control. Elemental concentrations were determined by comparison with the internal standard [13]. Extraction efficiency was confirmed through the analysis of International certified reference materials (ERM-CE278k Mussel Muscle, Table 2).

Table 2. Mussel (ERM-CE278k) certified and analysed elemental values, uncertainty (mg/kg) and calculated extraction efficiency (average \pm standard deviation, $N=5$ ).

\begin{tabular}{ccccc}
\hline Element & Certified Value & Uncertainty & Measured Value & Extraction Efficiency (\%) \\
\hline $\mathrm{Cr}$ & 0.73 & 0.22 & $0.67 \pm 0.10$ & $91.3 \pm 5.3$ \\
$\mathrm{Mn}$ & 4.88 & 0.24 & $3.35 \pm 0.10$ & $68.6 \pm 1.9$ \\
$\mathrm{Fe}$ & 161.0 & 8.0 & $198.03 \pm 0.67$ & $123.0 \pm 0.4$ \\
$\mathrm{Ni}$ & 0.69 & 0.15 & $0.78 \pm 0.05$ & $113.1 \pm 5.8$ \\
$\mathrm{Cu}$ & 5.98 & 0.27 & $7.10 \pm 0.07$ & $118,8 \pm 1.0$ \\
$\mathrm{Zn}$ & 71.0 & 4.0 & $73.29 \pm 0.28$ & $103.2 \pm 0.4$ \\
$\mathrm{As}$ & 6.7 & 0.4 & $7.25 \pm 0.07$ & $108.2 \pm 0.9$ \\
$\mathrm{Se}$ & 1.62 & 0.12 & $1.51 \pm 0.03$ & $93.3 \pm 1.9$ \\
$\mathrm{Rb}$ & 2.46 & 0.16 & $2.45 \pm 0.05$ & $99.6 \pm 1.9$ \\
$\mathrm{Sr}$ & 19.0 & 0.0 & $18.55 \pm 0.34$ & $97.6 \pm 1.8$ \\
$\mathrm{Cd}$ & 0.336 & 0.025 & $2.47 \pm 0.02$ & $96.6 \pm 4.5$ \\
$\mathrm{~Pb}$ & 2.18 & 0.18 & & $113.3 \pm 2.1$ \\
\hline
\end{tabular}

For food safety purposes, element concentrations were compared against available regulatory safety values, specifically for $\mathrm{Pb}(0.20 \mathrm{mg} / \mathrm{kg}), \mathrm{Cu}(30 \mathrm{mg} / \mathrm{kg}), \mathrm{Zn}(40 \mathrm{mg} / \mathrm{kg})$, $\mathrm{Mn}(1 \mathrm{mg} / \mathrm{kg}), \mathrm{Ni}(80 \mathrm{mg} / \mathrm{kg}), \mathrm{Fe}(43 \mathrm{mg} / \mathrm{kg})$ and $\mathrm{Cr}(15 \mathrm{mg} / \mathrm{kg})$, according to international guidelines [43-45]. For human consumption suitability assessment, a ratio between the individual measured elemental value and the established threshold for the same element was calculated. Ratio values above one indicate elemental concentrations above the recommended international thresholds for human consumption.

\subsection{Statistical and Chemometric Analysis}

Non-parametric Kruskal-Wallis with Bonferroni post hoc test was used for pairwise comparisons between the elemental concentrations of the individuals collected at the different geographical areas and were performed in R-Studio Version 1.4.1717 using the agricolae package [46]. Boxplots with probability density of the data at different values smoothed by a kernel density estimator were computed and plotted using ggplot2 [47] package in R-Studio Version 1.4.1717. Spearman correlation coefficients and statistical significance among elements concentration in the peduncle of the analysed individuals were computed using the corrplot [48] package in R-Studio Version 1.4.1717.

For the chemometric approach, five multivariate statistical methodologies were employed. The Primer 6 (version 6.1.13, with PERMANOVA + addon version 1.0.3) software [49] was used to carry out multivariate statistical analyses using non-parametric multivariate analysis packages. Following data transformation $(\log x+1)$ and dispersion weighting, the resemblance matrix of all variables (based on Euclidean distances) was analysed using canonical analysis of principal coordinates (CAP), in order to evaluate the ability to successfully classify individuals to their collection areas. This multivariate approach is insensitive to heterogeneous data and frequently used to compare different sample groups using the intrinsic characteristics (elemental concentrations) of each group [13,50]. Variables' relative importance was calculated by dividing the maximum absolute Spearman correlation coefficient of each variable with the canonical axis CAP1 and CAP2 by the sum 
of all variables' maximum absolute Spearman correlation coefficients with the canonical axis CAP1 and CAP2.

Partial least-squares discriminant analysis (PLS-DA) and variable importance in projection partial least-squares discriminant analysis (VIP-PLS-DA) were performed using the DiscriMiner package [51] in R-Studio Version 1.4.1717. For VIP-PLS-DA analysis, only variables with a VIP score $>1$ were included. Variable relative importance was calculated by dividing the VIP score of each variable by the sum of all VIP scores.

Linear discriminant analysis (LDA) was computed using the MASS package [52] in RStudio Version 1.4.1717. For LDA, normality of the data in each class, as well as covariance between sample matrixes, were ensured. The complete sample data was divided into $40 \%$ of the samples data set for model training, and the remaining $60 \%$ of the samples data set was used for the model test. Variable relative importance was calculated by dividing the sum of the absolute value of each variable first two linear discriminants with the whole variable dataset sum of the absolute value of the first two linear discriminants. Stepwise linear discriminant analysis (S-LDA) was computed using the klaR package [53] in R-Studio Version 1.4.1717. Stepwise variable selection was set in both directions (forward and backwards), with a 0.01 least improvement of performance measure desired to include or exclude any variable. The number of variables to be included was not limited. Variable relative importance was calculated by dividing each variable increment in accuracy with the sum of the selected variables of increment in accuracy.

Random forests (RF) were computed using the randomForest package [54] in R-Studio Version 1.4.1717. The maximum number of trees was set to 500, which proved to be enough to stabilize the error of the analysis. Variable relative importance was calculated by dividing each variable Gini accuracy by the sum of all variables Gini accuracies.

All chemometric approaches generated confusion matrixes used for the evaluation of the multivariate statistical approach performance in correctly classifying the sample provenance according to their elemental profile.

Models' performances in internal and external validation were evaluated in terms of accuracy (\%), sensitivity (\%), and specificity (\%) according to [55]. Model overall accuracy was calculated by dividing the number of correctly classified samples by the total number of samples.

\section{Conclusions}

Stalked barnacles are among the most valuable crustacean resources from the Portuguese rocky shores, having a high socio-economic relevance allied to high market value, reinforcing the need to develop analytical techniques coupled with chemometric approaches that can efficiently trace the geographical origin of these seafood products. The high number of elements typically found in these filter feeder animals introduces a background noise in traditional non-selective multivariate approaches, such as CAP. The application of variable selection approaches such as S-LDA provided a high accuracy degree in classifying the samples according to their harvesting area while reducing the number of elements needed for this classification. Moreover, the selected elements are similar to the ones selected by other approaches, reinforcing the reliability of this selection. Simultaneously, and given the gastronomical role of stalked barnacles as delicacies, this approach also offers important information regarding the concentration of elements with recommended thresholds for human consumption, providing valuable insights into the food safety status of this seafood product. The development of the traceability chemometric tools, based on the untargeted elemental profiles of the edible peduncle of P. pollicipes, is a novel technique that allows to track the origin of this high-value commercialized and regulated food resource, thus providing relevant data regarding the capture effort of these organisms, aside from the information provided by the fishermen. Ultimately, this information can be used for updating and revising management schemes that allow maintaining a sustainable harvest of these organisms, while simultaneously informing the consumers about their safety and provenance. 
Supplementary Materials: The following can be downloaded online. Table S1. Average, maximum and minimum concentrations ( $\mathrm{mg} / \mathrm{kg} \mathrm{ww}$ ) of all the analysed elements $(N=15$ per site).

Author Contributions: Conceptualization, B.D. and V.F.F.; methodology, R.M.; formal analysis, B.D.; investigation, R.M., B.D. and V.F.F.; resources, B.D, D.J., T.C. and M.S.; data curation, B.D.; writingoriginal draft preparation, B.D.; writing—review and editing, R.M., I.A.D., S.E.T., M.S., D.J., T.C., I.C. and V.F.F.; project administration, B.D. and M.S.; funding acquisition, B.D. and M.S. All authors have read and agreed to the published version of the manuscript.

Funding: The authors would like to thank Fundação para a Ciência e a Tecnologia (FCT) for funding the research via the project grant UIDB/04292/2020. Work was also funded by MAR2020 program via the Projects MarCODE (MAR-01.03.01-FEAMP-0047) and AQUA-PROSPECT (MAR02.02.01-FEAMP-0005). B. Duarte, S.E. Tanner and V. Fonseca were supported by research contracts (CEECIND/00511/2017, DL57/2016/CP1479/CT0022 and DL57/2016/CP1479/CT0024). M. Silva was supported by AQUA-PROSPECT project (MAR-02.02.01-FEAMP-0005).

Institutional Review Board Statement: Not applicable.

Informed Consent Statement: Not applicable.

Data Availability Statement: The data presented in this study are available on request from the corresponding author.

Acknowledgments: We would like to thank Francesco Maresca and David Mateus for their assistance during the fieldwork.

Conflicts of Interest: The authors declare no conflict of interest. The funders had no role in the design of the study, in the collection, analyses, or interpretation of data, in the writing of the manuscript, or in the decision to publish the results.

Sample Availability: Samples of the compounds are not available from the authors.

\section{References}

1. Reilly, A. Overview of Food Fraud in the Fisheries Sector; Fisheries and Aquaculture Circular; Food and Agriculture Organization of the United Nations (FAO): Rome, Italy, 2018; p. 32.

2. He, J. From Country-of-Origin Labelling (COOL) to Seafood Import Monitoring Program (SIMP): How Far Can Seafood Traceability Rules Go? Mar. Policy 2018, 96, 163-174. [CrossRef]

3. European Parliament and Council of the European Union. Regulation (EU) No 1379/2013 of the European Parliament and of the Council of 11 December 2013 on the Common Organization of the Markets in Fishery and Aquaculture Products, Amending Council Regulations (EC) No 1184/2006 and (EC) No 1224/2009 and Repealing Council Regulation (EC) No 104/2000, European Parliament and Council of the European Union: Brussels, Belgium, 11 December 2013; Volume 354.

4. Leal, M.C.; Pimentel, T.; Ricardo, F.; Rosa, R.; Calado, R. Seafood Traceability: Current Needs, Available Tools, and Biotechnological Challenges for Origin Certification. Trends Biotechnol. 2015, 33, 331-336. [CrossRef] [PubMed]

5. Galimberti, A.; Labra, M.; Sandionigi, A.; Bruno, A.; Mezzasalma, V.; De Mattia, F. DNA Barcoding for Minor Crops and Food Traceability. Adv. Agric. 2014, 2014, 831875. [CrossRef]

6. Ogden, R. Fisheries Forensics: The Use of DNA Tools for Improving Compliance, Traceability and Enforcement in the Fishing Industry. Fish Fish. 2008, 9, 462-472. [CrossRef]

7. Portarena, S.; Farinelli, D.; Lauteri, M.; Famiani, F.; Esti, M.; Brugnoli, E. Stable Isotope and Fatty Acid Compositions of Monovarietal Olive Oils: Implications of Ripening Stage and Climate Effects as Determinants in Traceability Studies. Food Control 2015, 57, 129-135. [CrossRef]

8. Ricardo, F.; Gonçalves, D.; Pimentel, T.; Mamede, R.; Rosário, M.; Domingues, M.; Lillebø, A.I.; Calado, R. Prevalence of Phylogenetic over Environmental Drivers on the Fatty Acid Profiles of the Adductor Muscle of Marine Bivalves and Its Relevance for Traceability. Ecol. Indic. 2021, 129, 108017. [CrossRef]

9. Montet, D.; Nguyen, D.D.L.; Sheikha, A.F.E.; Condur, A.; Métayer, I.; Loiseau, G. Application of PCR-DGGE in Determining Food Origin. Asp. Appl. Biol. 2008, 87, 12.

10. Albuquerque, R.; Queiroga, H.; Swearer, S.E.; Calado, R.; Leandro, S.M. Harvest Locations of Goose Barnacles Can Be Successfully Discriminated Using Trace Elemental Signatures. Sci. Rep. 2016, 6, 27787. [CrossRef]

11. Bennion, M.; Morrison, L.; Shelley, R.; Graham, C. Trace Elemental Fingerprinting of Shells and Soft Tissues Can Identify the Time of Blue Mussel (Mytilus Edulis) Harvesting. Food Control 2021, 121, 107515. [CrossRef]

12. Davis, R.P.; Boyd, C.E.; Davis, D.A. The Utility of Discriminant Analysis to Determine the Geographic Origin of Commercially Important Seafood and Aquaculture Species: A Meta-Analysis. Rev. Fish. Sci. Aquac. 2021, 29, 791-799. [CrossRef] 
13. Duarte, B.; Duarte, I.A.; Caçador, I.; Reis-Santos, P.; Vasconcelos, R.P.; Gameiro, C.; Tanner, S.E.; Fonseca, V.F. Elemental Fingerprinting of Thornback Ray (Raja Clavata) Muscle Tissue as a Tracer for Provenance and Food Safety Assessment. Food Control 2022, 133, 108592. [CrossRef]

14. Mamede, R.; Ricardo, F.; Gonçalves, D.; Ferreira da Silva, E.; Patinha, C.; Calado, R. Assessing the Use of Surrogate Species for a More Cost-Effective Traceability of Geographic Origin Using Elemental Fingerprints of Bivalve Shells. Ecol. Indic. 2021, 130, 108065. [CrossRef]

15. Vieira, S.; Barrulas, P.; Chainho, P.; Dias, C.B.; Sroczyńska, K.; Adão, H. Spatial and Temporal Distribution of the Multi-Element Signatures of the Estuarine Non-Indigenous Bivalve Ruditapes Philippinarum. Biol. Trace Elem. Res. 2022, 200, 385-401. [CrossRef]

16. Kelly, S.; Heaton, K.; Hoogewerff, J. Tracing the Geographical Origin of Food: The Application of Multi-Element and Multi-Isotope Analysis. Trends Food Sci. Technol. 2005, 16, 555-567. [CrossRef]

17. Lim, C.M.; Carey, M.; Williams, P.N.; Koidis, A. Rapid Classification of Commercial Teas According to Their Origin and Type Using Elemental Content with X-Ray Fluorescence (XRF) Spectroscopy. Curr. Res. Food Sci. 2021, 4, 45-52. [CrossRef]

18. Rajapaksha, D.; Waduge, V.; Padilla-Alvarez, R.; Kalpage, M.; Rathnayake, R.M.N.P.; Migliori, A.; Frew, R.; Abeysinghe, S.; Abrahim, A.; Amarakoon, T. XRF to Support Food Traceability Studies: Classification of Sri Lankan Tea Based on Their Region of Origin. X-ray Spectrom. 2017, 46, 220-224. [CrossRef]

19. López, D.A.; López, B.A.; Pham, C.K.; Isidro, E.J.; De Girolamo, M. Barnacle Culture: Background, Potential and Challenges. Aquac. Res. 2010, 41, e367-e375. [CrossRef]

20. Aguión, A.; Ojea, E.; García-Flórez, L.; Cruz, T.; Garmendia, J.M.; Davoult, D.; Queiroga, H.; Rivera, A.; Acuña-Fernández, J.L.; Macho, G. Establishing a Governance Threshold in Small-Scale Fisheries to Achieve Sustainability. Ambio 2021, 51, 652-665. [CrossRef]

21. Jacinto, D.; Cruz, T.; Silva, T.; Castro, J.J. Stalked Barnacle (Pollicipes Pollicipes) Harvesting in the Berlengas Nature Reserve, Portugal: Temporal Variation and Validation of Logbook Data. ICES J. Mar. Sci. 2010, 67, 19-25. [CrossRef]

22. Jacinto, D.; Cruz, T.; Silva, T.; Castro, J.J. Management of the Stalked Barnacle (Pollicipes Pollicipes) Fishery in the Berlengas Nature Reserve (Portugal): Evaluation of Bag and Size Limit Regulation Measures. Sci. Mar. 2011, 75, 439-445. [CrossRef]

23. Sousa, A.; Jacinto, D.; Penteado, N.; Martins, P.; Fernandes, J.; Silva, T.; Castro, J.J.; Cruz, T. Patterns of Distribution and Abundance of the Stalked Barnacle (Pollicipes Pollicipes) in the Central and Southwest Coast of Continental Portugal. J. Sea Res. 2013, 83, 187-194. [CrossRef]

24. Caçador, I.; Costa, J.L.; Duarte, B.; Silva, G.; Medeiros, J.P.; Azeda, C.; Castro, N.; Freitas, J.; Pedro, S.; Almeida, P.R.; et al Macroinvertebrates and Fishes as Biomonitors of Heavy Metal Concentration in the Seixal Bay (Tagus Estuary): Which Species Perform Better? Ecol. Indic. 2012, 19, 184-190. [CrossRef]

25. Fonseca, V.F.; França, S.; Duarte, B.; Caçador, I.; Cabral, H.N.; Mieiro, C.L.; Coelho, J.P.; Pereira, E.; Reis-Santos, P. Spatial Variation in Mercury Bioaccumulation and Magnification in a Temperate Estuarine Food Web. Front. Mar. Sci. 2019, 6, 117. [CrossRef]

26. Reis-Santos, P.; Tanner, S.E.; França, S.; Vasconcelos, R.P.; Gillanders, B.M.; Cabral, H.N. Connectivity within Estuaries: An Otolith Chemistry and Muscle Stable Isotope Approach. Ocean. Coast. Manag. 2015, 118, 51-59. [CrossRef]

27. Cruz, T.; Jacinto, D.; Sousa, A.; Penteado, N.; Pereira, D.; Fernandes, J.N.; Silva, T.; Castro, J.J. The State of the Fishery, Conservation and Management of the Stalked Barnacle Pollicipes Pollicipes in Portugal. Mar. Environ. Res. 2015, 112, 73-80. [CrossRef]

28. Varrà, M.O.; Husáková, L.; Patočka, J.; Ghidini, S.; Zanardi, E. Multi-Element Signature of Cuttlefish and Its Potential for the Discrimination of Different Geographical Provenances and Traceability. Food Chem. 2021, 356, 129687. [CrossRef]

29. Sarmiento, J.L.; Gruber, N. Ocean Biogeochemical Dynamics; Princeton University Press: Princeton Woodstock, NJ, USA, 2006.

30. Barnes, M. Pedunculate Cirripedes of the Genus Pollicipes. Oceanogr. Mar. Biol. 1996, 4, 303-394.

31. Rodríguez-Navarro, A.; Rubio, F. High-Affinity Potassium and Sodium Transport Systems in Plants. J. Exp. Bot. 2006, 57, 1149-1160. [CrossRef]

32. Smith, G. Step Away from Stepwise. J. Big Data 2018, 5, 32. [CrossRef]

33. Rashid, N.A.; Hussain, W.S.E.C.; Ahmad, A.R.; Abdullah, F.N. Performance of Classification Analysis: A Comparative Study between PLS-DA and Integrating PCA+LDA. Math. Stat. 2019, 7, 24-28. [CrossRef]

34. Brereton, R.G.; Lloyd, G.R. Partial Least Squares Discriminant Analysis: Taking the Magic Away. J. Chemom. 2014, 28, 213-225. [CrossRef]

35. Ricardo, F.; Génio, L.; Costa Leal, M.; Albuquerque, R.; Queiroga, H.; Rosa, R.; Calado, R. Trace Element Fingerprinting of Cockle (Cerastoderma Edule) Shells Can Reveal Harvesting Location in Adjacent Areas. Sci. Rep. 2015, 5, 11932. [CrossRef]

36. Cruz, T.; Hawkins, S.J. Reproductive Cycle of Pollicipes Pollicipes at Cabo De Sines, South-West Coast of Portugal. J. Mar. Biol. Assoc. United Kingd. 1998, 78, 483-496. [CrossRef]

37. Costas-Rodríguez, M.; Lavilla, I.; Bendicho, C. Classification of Cultivated Mussels from Galicia (Northwest Spain) with European Protected Designation of Origin Using Trace Element Fingerprint and Chemometric Analysis. Anal. Chim. Acta 2010, 664, 121-128. [CrossRef] [PubMed]

38. Vasconcelos, R.P.; Reis-Santos, P.; Fonseca, V.; Maia, A.; Ruano, M.; França, S.; Vinagre, C.; Costa, M.J.; Cabral, H. Assessing Anthropogenic Pressures on Estuarine Fish Nurseries along the Portuguese Coast: A Multi-Metric Index and Conceptual Approach. Sci. Total Environ. 2007, 374, 199-215. [CrossRef] [PubMed]

39. Reis, P.A.; Salgado, M.A.; Vasconcelos, V. Goose Barnacle Pollicipes Pollicipes as Biomonitor of Metal Contamination in the Northwest Coast of Portugal. Environ. Monit. Assess. 2012, 184, 6987-7000. [CrossRef] 
40. Reis, P.A.; Salgado, M.A.; Vasconcelos, V. Seasonal Variation of Metal Contamination in the Barnacles Pollicipes Pollicipes in Northwest Coast of Portugal Show Clear Correlation with Levels in the Surrounding Water. Mar. Pollut. Bull. 2013, 70, 155-161. [CrossRef]

41. Towett, E.K.; Shepherd, K.D.; Cadisch, G. Quantification of Total Element Concentrations in Soils Using Total X-Ray Fluorescence Spectroscopy (TXRF). Sci. Total Environ. 2013, 463-464, 374-388. [CrossRef]

42. Environmental Protection Agency (EPA). Test Method 3052: Microwave Assisted Acid Digestion of Siliceous and Organically Based Matrices; Environmental Protection Agency (EPA): Washington, DC, USA, 1996; p. 20.

43. European Commission Commission Regulation (EC) No 1881/2006 of 19 December 2006 Setting Maximum Levels for Certain Contaminants in Foodstuffs, European Commission: Tokyo, Japan, 2006.

44. FAO/WHO Evaluation of Certain Food Additives and the Contaminants Mercury, Lead and Cadmium; WHO Technical Report; WHO: Geneva, Switzerland, 1989.

45. FAO/WHO List of Maximum Levels Recommended for Contaminants by the Joint FAO/WHO Codex Alimentarius Commission; Second Series CAC/FAL; WHO: Rome, Italy, 1984; p. 8.

46. De Mendiburu, F.; Simon, R. Agricolae-Ten Years of an Open Source Statistical Tool for Experiments in Breeding, Agriculture and Biology. PeerJ Prepr. 2015, 3, e1404v1.

47. Wickham, H. Ggplot2: Elegant Graphics for Data Analysis; Use R! Springer: New York, NY, USA, 2009, ISBN 978-0-387-98141-3.

48. Taiyun. Taiyun/Corrplot; Taiyun: Guangzhou, China, 2021.

49. Clarke, K.R.; Gorley, R.N. PRIMER v6: User Manual/Tutorial; PRIMER-E: Plymouth, UK, 2006; Volume 192. [CrossRef]

50. Duarte, B.; Carreiras, J.; Feijão, E.; Reis-Santos, P.; Caçador, I.; Matos, A.R.; Fonseca, V.F. Fatty Acid Profiles of Estuarine Macroalgae Are Biomarkers of Anthropogenic Pressures: Development and Application of a Multivariate Pressure Index. Sci. Total Environ. 2021, 788, 147817. [CrossRef]

51. Sanchez, G. Package 'DiscriMiner'. 2013. Available online: https://citeseerx.ist.psu.edu/viewdoc/download?doi=10.1.1.408.514 $5 \&$ rep $=$ rep $1 \&$ type $=$ pdf (accessed on 26 January 2022).

52. Venables, W.N.; Ripley, B.D. Modern Applied Statistics with S, 4th ed.; Springer: Berlin, Germany, 2002.

53. Röver, C.; Raabe, N.; Luebke, K.; Ligges, U. KlaR: A Package Including Various Classification Tools; University Dortmund: Dortmund, Germany, 2004.

54. Liaw, A.; Wiener, M. Classification and Regression by RandomForest. $R$ News 2002, 2-3, 18-22.

55. Fawcett, T. An Introduction to ROC Analysis. Pattern Recognit. Lett. 2006, 27, 861-874. [CrossRef] 